TP Periodica Polytechnica Civil Engineering

\author{
62(4), pp. 956-962, 2018 \\ https://doi.org/10.3311/PPci.10910 \\ Creative Commons Attribution (i)
}

RESEARCH ARTICLE

\section{An Investigation of Crack Propagation in Steel Fiber-Reinforced Composite Beams}

\author{
Adam Soto $^{1}$, Fariborz M. Tehrani ${ }^{1 *}$
}

Received 30 April 2017; Revised 08 January 2018; Accepted 09 May 2018

\begin{abstract}
This paper investigates the cracking phenomena of fiber-reinforced concrete in steel and concrete composite beam systems. Various parameters contribute to the crack development and weakening of the composite system, while the concrete slab is bonded to the steel beam. The weakening can result from the longitudinal shear stress that causes cracking from shear connectors, cracking from tensile forces, crushing due to compressive forces and also cracking from concrete shrinkage. These cracks can contribute to premature failure of the composite beam. This paper investigates fiber reinforcement as a solution to decrease the amount of cracking in composite beams. The presented methodology includes experimental studies to evaluate cracking characteristics and strength of fiber-reinforced composite beams. Parameters of the study included spacing between studs, application of welded wire reinforcement, and fiber reinforcement. Results indicate the effectiveness of fiber-reinforcement in reducing crack widths and number of cracks, even though, spacing between studs and presence of welded wire were essential in crack control. Further, fiber-reinforced specimens showed higher compressive and tensile strength by $30 \%$ and $70 \%$ respectively. The deflection at the peak load also showed a 23\% decrease for the specimen with hybrid fiber-wire reinforcement in comparison with the specimen reinforced with welded wire only.
\end{abstract}

\section{Keywords}

composite construction, composite beams, fiber reinforced composites, fiber reinforced concrete, steel fibers, cracking

\footnotetext{
1 Department of Civil and Geomatics Engineering Lyles College of Engineering,

California State University,

2320 E. San Ramon Avenue, M/S EE94, Fresno, CA 93740-8030, U.S.A.

* Corresponding author, email: ftehrani@csufresno.edu
}

\section{Introduction}

Composite floors are common in many buildings and bridges [1]. These floor systems often include concrete slabs placed on metal decks and supported by steel beams [2]. The composite action between concrete and metal deck is often neglected in design, unless the minimal shear resistance due to bond and friction forces is enhanced by mechanical devices [3]. But, the partial or full composite actions between concrete and steel beam are generally satisfied using shear connectors such as steel studs [4]. As a result, a longitudinal shear force will develop at the interface of concrete and steel. This longitudinal shear force can cause cracking in the concrete [5]. In addition, tensile and compressive stresses due to the flexure of composite beam may cause cracking or crushing in the concrete [6]. Cracks due to concrete shrinkage during setting of the concrete also contribute to the crack propagation after loading [7].

Conventional steel reinforcement is a common method to reduce number of cracks and control crack propagation in concrete, but, it often results in rebar congestion and extra labor costs [1]. Thus, fiber-reinforcement using short discontinued fibers has gained some popularity as a supplemental method, if not a substitute, for conventional continuous reinforcement. In particular, application of steel fibers has been shown to be effective in reduction of crack width and spacing, and thus, increases the ductility and the overall strength of the composite beam [8].

This paper deals with an investigation of the cracking phenomena between concrete and steel in composite beams. The purpose of presented experimental studies is to evaluate the cracking behavior of composite beams with the inclusion of steel fibers. Experimental studies include flexural tests to evaluate the effect of fiber reinforcement on the behavior of composite beams and the crack propagation within the concrete slab. An analysis is presented to compare the results with theoretical values and show the effectiveness of fiber reinforcement. 


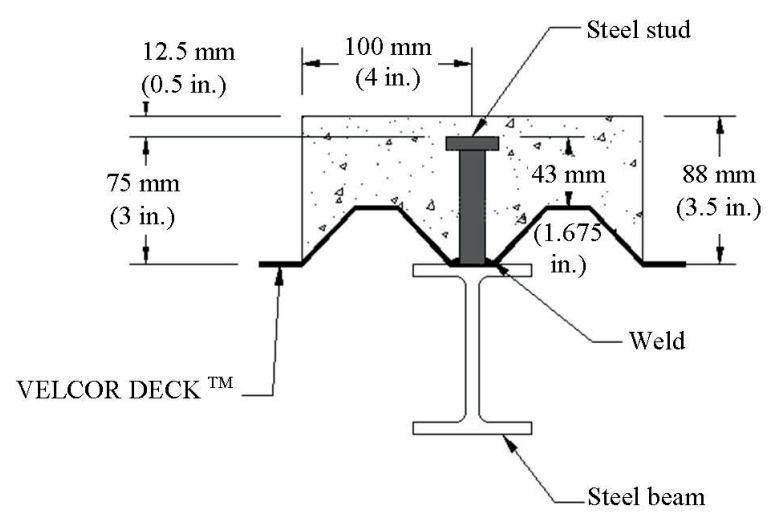

Fig. 1 Cross-section of composite beam specimens

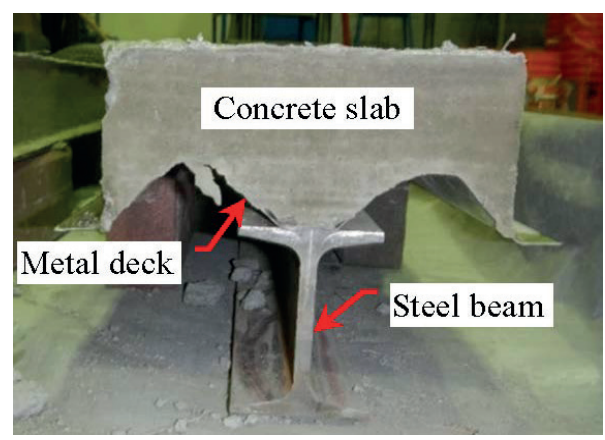

Fig. 2 A typical composite beam specimen

\section{Material and methods}

\subsection{Composite beam}

Control flexural specimens contain plain concrete reinforced with welded wire mesh for comparison purposes. The crack propagation for each specimen was observed and analyzed in respect to number and width of cracks. Further, the load-deflection relationships were compared with theoretical analyses.

Each composite beam consists of a concrete slab resting upon a steel beam. The concrete slab will be bonded to the steel beam by means of shear connectors as shown in the Figure 1. Also, adequate amount of sheer connectors is designed so the ultimate strength of the composite beam was no longer governed by the strength of studs. Further, the design aimed to place the plastic neutral axis (PNA) within the steel section to avoid any tensile crack in the concrete. The composite beam was designed following the ANSI/AISC 360 specifications [9]. The design was adjusted to minimize the thickness of concrete above the stud in order to enhance the reflection of cracks on the surface of concrete for visual observation.

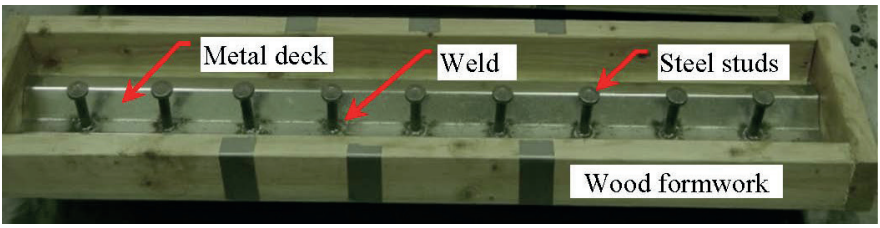

Fig. 4 Concrete formwork with pre-welded studs

Figure 1 shows the typical cross-section of the composite beam. All steel beams are American Standard S $4 \times 9.5$ with $0.1 \mathrm{~m}$ (4 in.) depth and $14.1 \mathrm{~kg} / \mathrm{m}(9.5 \mathrm{lb} / \mathrm{ft})$ weight. The length of the steel beam, similar to the length of the composite beam, was $1.2 \mathrm{~m}$ (48 in.). A steel deck holds the concrete slab in place on top of the steel beam. The steel deck was the 22 gage Deep Vercor TM deck with $8.3 \mathrm{~kg} / \mathrm{m}^{2}$ (1.7 psf) weight and $33 \mathrm{~mm}$ (1-5/16 in.) depth. The specified minimum yield stress of the metal deck was $552 \mathrm{MPa}(80 \mathrm{ksi})$ [10].

The orientation of the ribs was parallel to the steel beam to allow more flexibility for spacing between studs. The steel studs were headed concrete anchors with $15.9 \mathrm{~mm}$ (5/8 in.) diameter, $81.0 \mathrm{~mm}$ (3-3/16 in.) length, and $4.76 \mathrm{~mm}$ (3/16 in.) burn off due to welding. The yield stress and the tensile strength of studs were recorded as $414 \mathrm{MPa}(60 \mathrm{ksi})$ and $448 \mathrm{MPa}$ (65 ksi), respectively. There were two types of reinforcement within the concrete slab. The first type was a welded wire mesh consisting of plain steel wires with $2.67 \mathrm{~mm}$ (0.105 in.) diameter at $25.4 \mathrm{~mm}$ (1 in.) spacing. The weight of the welded wire was approximately 1.73 $\mathrm{kg} / \mathrm{m}^{2}(0.35 \mathrm{psf})$. The second type of reinforcement was Novocon ${ }^{\circledR} 1050$ hooked-end steel fibers manufactured from colddrawn wire, with $50 \mathrm{~mm}$ ( 2 in.) length and an aspect ratio of 50, that is $1 \mathrm{~mm}$ (0.039 in.) diameter. The volumetric fiber content was $0.75 \%$, which results in approximately $59 \mathrm{~kg} / \mathrm{m}^{3}$ (99 pcy) or $4.24 \mathrm{~kg} / \mathrm{m}^{2}$ (0.87 psf) fiber content by weight. The tensile strength of fibers was specified to be $1050 \mathrm{MPa}(152 \mathrm{ksi})$ [11].

Figure 2 shows a typical constructed composite beam after removing formworks.

Figures 3 and 4 show a typical stud layout for specimens. There were total of 12 specimens, with six of them serving as control specimens. These specimens were reinforced with welded wire mesh. There were also three different types of stud spacing for these specimens, including $100 \mathrm{~mm}$ (4 in.), $125 \mathrm{~mm}$ (5 in.), and $150 \mathrm{~mm}$ (6 in.). Varying the spacing allows different amounts of shear forces acting on each stud and consequent cracking in concrete.

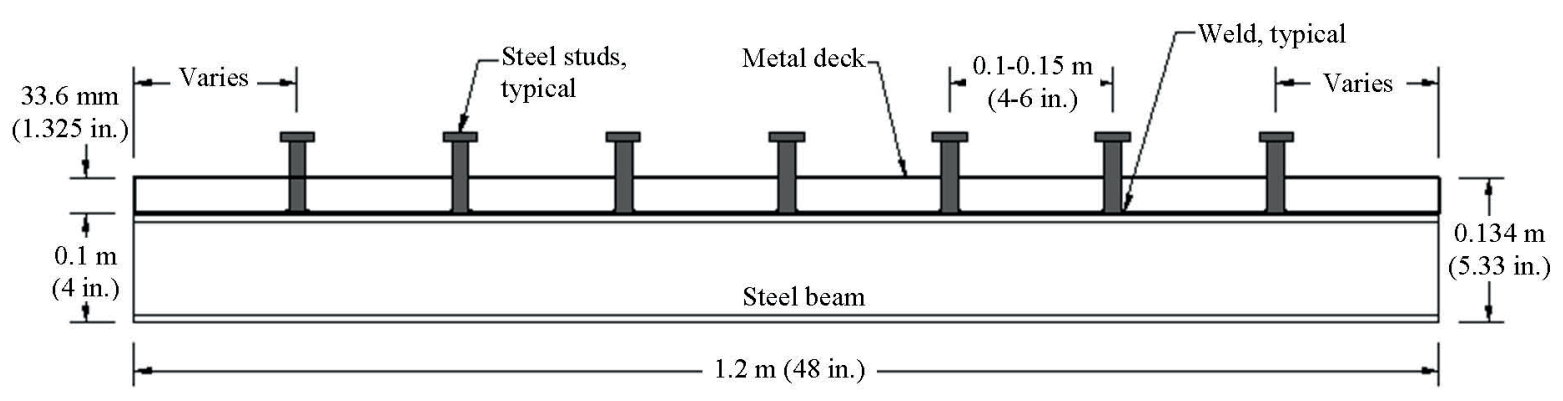

Fig. 3 Stud layout 
Table 1 Mix proportion of concrete

\begin{tabular}{lc}
\hline Mix Properties & $\mathrm{kg} / \mathrm{m}^{3}(\mathrm{lbs} / \mathrm{cy})$ \\
\hline Portland cement, Type I-II & $401(681)$ \\
Water, water-to-cement ratio $=0.47$ & $190(322)$ \\
Course aggregate, max size $=19 \mathrm{~mm}(3 / 4$ in. $)$ & $929(1576)$ \\
Fine aggregate & $826(1403)$ \\
Steel fiber, 0.75\% volumetric content & $59(99)$ \\
\hline
\end{tabular}

Table 2 Average strength of concrete mix

\begin{tabular}{lcc}
\hline Concrete mix & Compression MPa (ksi) & Tension MPa (ksi) \\
\hline Plain concrete & $15.9(2.31)$ & $2.17(0.315)$ \\
Fiber reinforced concrete & $20.5(2.97)$ & $3.77(0.547)$ \\
\hline
\end{tabular}

\subsection{Mix design}

Table 1 shows the mix proportions for the concrete. Control specimens contained plain concrete as opposed to SFRC specimens that contained steel fibers. Steel fibers were added per manufacturer's specification and mixed for 75 rotations at a full mixing speed [11]. Specimens were wet cured according to AASHTO M 182 [12].

\section{Results}

\subsection{Compression and split-tension testing}

Table 2 contains the result of compression and split-tension tests on plain and fiber-reinforced concrete. Each data in this table is the average of minimum three samples per test per mix. Comparison of results in this table indicates that fiber-reinforcement has increased the tensile and compressive strengths by $74 \%$ and $29 \%$, respectively. Furthermore, figures 5 and 6 show the effect of fibers on the failure of specimens. In particular, the figure 6 shows how fibers have kept the splitting parts of the specimen together.

\subsection{Flexural testing}

Figure 7 depicts the testing configuration. The composite beams will undergo flexural tests to determine the cracking behavior of the specimens. The composite beams will be simply supported with a span of $0.84 \mathrm{~m}$ (33 in.) between supports. A two-point loading device will be applied at the top of the beam. The clear spacing between loads is $0.25 \mathrm{~m}$ (10 in.). Prior to flexural testing, strain gauge sensors were bonded to the mid-span of beams, including two gauges at the top of the concrete slab, and two gauges at the bottom of the steel flange (one on each side, top and bottom) to measure compressive and tensile strains, respectively. Each specimen was loaded at the rate of 0.13 to $0.17 \mathrm{~mm} / \mathrm{sec}(0.3-0.4 \mathrm{in} . / \mathrm{min}$.).

Figure 8 shows a failed beam under flexural load and an example of traced cracks on the specimen. This is a control specimen (specimen 2) with plain concrete and studs spaced every $0.15 \mathrm{~m}$ (6 in.). Circled areas indicate close-up of a sample area along the span of the beam. The crack widths were measured using a 9x comparator and reticle set from Edmund

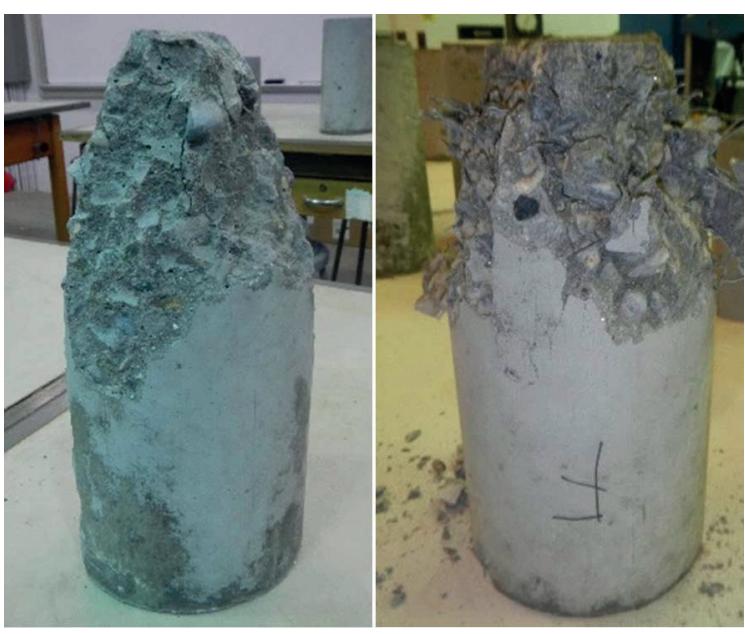

Fig. 5 Compressive failure of plain concrete (left) and fiber-reinforced concrete (right)

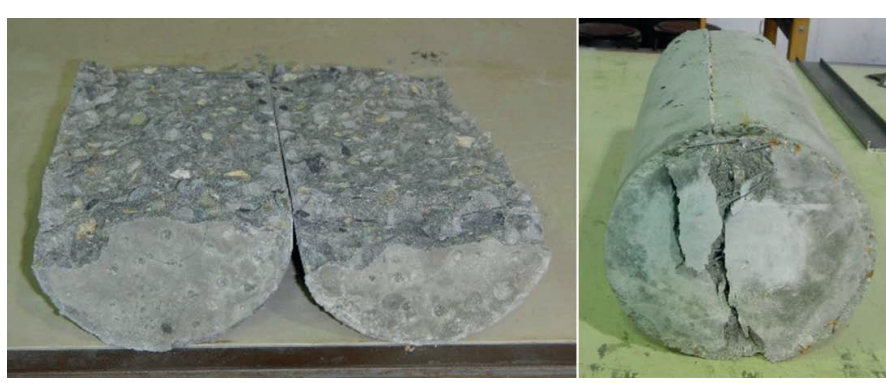

Fig. 6 Splitting tensile failure of plain concrete (left) and fiber-reinforced concrete (right)

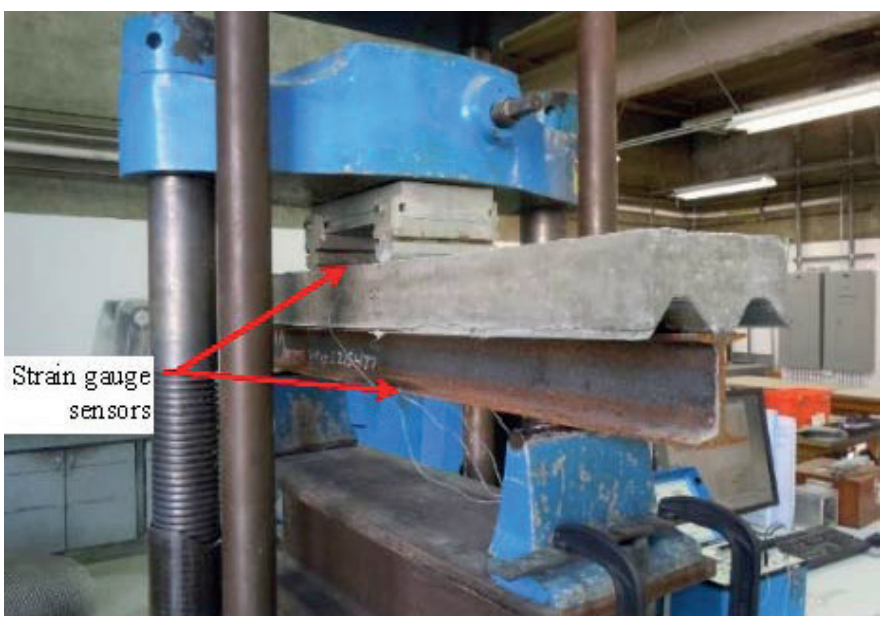

Fig. 7 Flexural test setup

Optics with the accuracy of nearly $0.1 \mathrm{~mm}$ (0.005 in.). Cracks were inspected throughout the test at every $22 \mathrm{kN}$ (5 kip). Sketches of crack propagation were developed after the failure of composite beam specimen. Table 3 contains sample data from these inspections for a single crack, marked as number 2 in the figure 8 . This process was repeated for top and sides of each specimen, as presented later here.

Recorded results includes the amount of cracking, crack locations, initial first crack, and crack widths for each specimen as shown in figures 11 to 22 , represented later in this paper. Comparison of theoretical and observed load-deflection relationships are also provided in figures 23 to 25, shown later. 


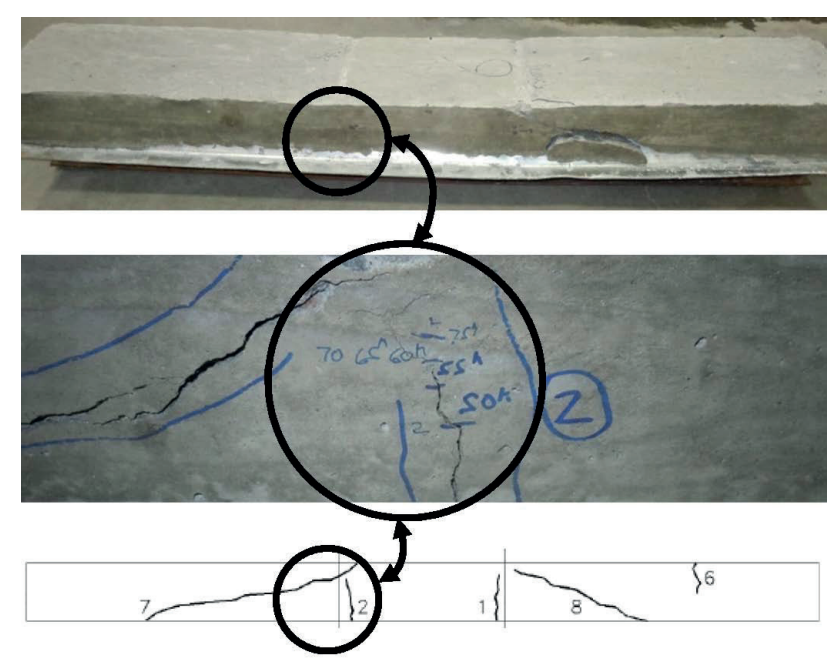

Fig. 8 A typical (control specimen) deflected beam (top), cracks (middle), and tracing (bottom)

Table 3 Sample records of a single crack (crack 2 in Figure 8)

\begin{tabular}{lcc}
\hline Load N (kip) & Crack width $\mathrm{mm}$ (in.) & Crack depth $\mathrm{mm}$ (in.) \\
\hline $222(50)$ & $0.25(0.010)$ & $31.5(1.241)$ \\
$245(55)$ & $0.38(0.015)$ & $44.1(1.736)$ \\
$267(60)$ & $0.51(0.020)$ & $51.1(2.010)$ \\
$289(65)$ & $0.64(0.025)$ & $51.1(2.010)$ \\
$311(70)$ & $0.76(0.030)$ & $51.1(2.010)$ \\
$333(75)$ & $1.40(0.055)$ & $58.2(2.291)$ \\
\hline
\end{tabular}

\begin{tabular}{lccc}
\multicolumn{4}{c}{ Table 4 Flexural test results } \\
\hline Specimen type & $\begin{array}{c}\text { Stud's spacing } \\
\text { mm (in.) }\end{array}$ & $\begin{array}{c}\text { Peak load } \\
\mathrm{kN}(\mathrm{kip})\end{array}$ & $\begin{array}{c}\text { Deflection at peak } \\
\text { load mm (in.) }\end{array}$ \\
\hline S6-PC-WW & $150(6)$ & $336.4(75.6)$ & $8.64(0.34)$ \\
S6-PC-WW & $150(6)$ & $340.9(76.6)$ & $11.9(0.47)$ \\
S5-PC-WW & $125(5)$ & $265.7(59.7)$ & $7.62(0.30)$ \\
S5-PC-WW & $125(5)$ & $345.3(77.6)$ & $11.4(0.45)$ \\
S4-PC-WW & $100(4)$ & $367.1(82.5)$ & $8.38(0.33)$ \\
S4-PC-WW & $100(4)$ & $363.6(81.7)$ & $11.2(0.44)$ \\
S6-SFRC & $150(6)$ & $211.8(47.6)$ & $4.32(0.17)$ \\
S6-SFRC & $150(6)$ & $289.7(65.1)$ & $9.65(0.38)$ \\
S5-SFRC & $125(5)$ & $205.6(46.2)$ & $5.59(0.22)$ \\
S5-SFRC & $125(5)$ & $326.2(73.3)$ & $8.38(0.33)$ \\
S4-SFRC & $100(4)$ & $334.6(75.2)$ & $10.4(0.41)$ \\
S4-SFRC-WW & $100(4)$ & $356.0(80.0)$ & $8.64(0.34)$ \\
\hline
\end{tabular}

Table 4 provides the maximum load and the deflection at the maximum load for each specimen. Considering the designed location of neutral axis and compressive nature of loads on concrete, fibers did not have a major impact on the stress-strain relationship of composite beams. But, the effect of spacing between studs on the recorded peak load is apparent in this table.

\subsection{Theory and calculations}

A moment-curvature analysis was performed on a discretized model of composite section (Figure 9) using modified Kent-Park model for concrete and an elasto-plastic model with

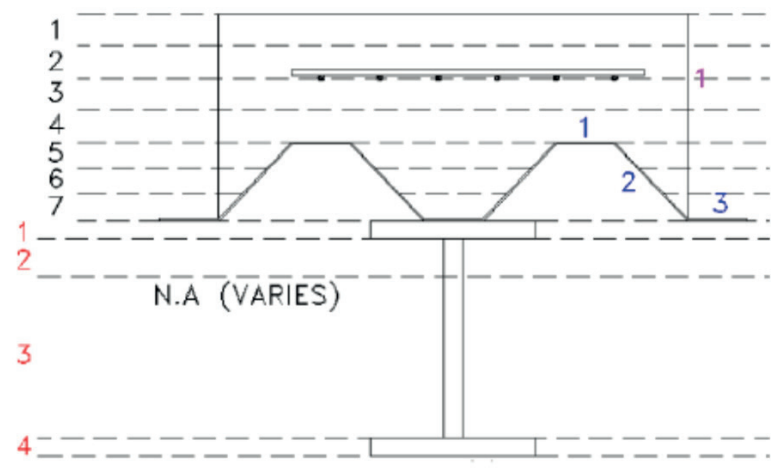

Fig. 9 Discretization of the composite beam and layer numbering

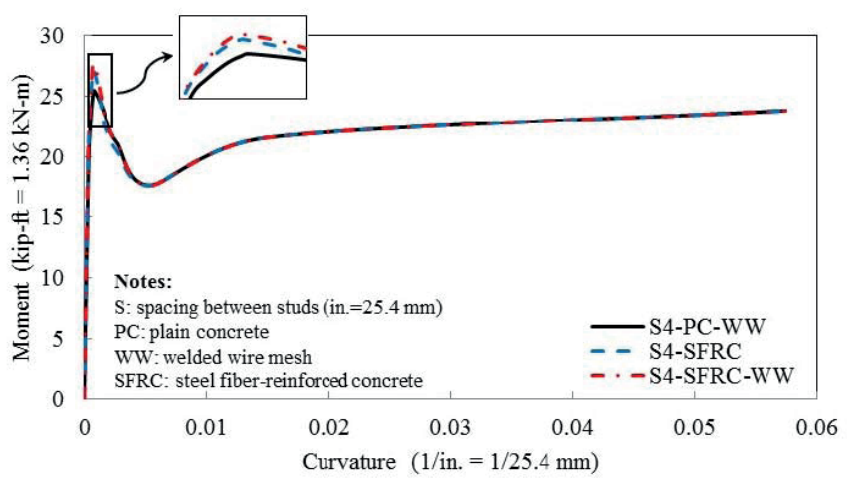

Fig. 10 Sample moment-curvature relationships

strain hardening for steel [13]. Figure 10 presents moment-curvature relationships for selected configurations. This figure shows slight increase in the peak moment due to presence of steel fibers. Load-deflection curves were obtained from this moment-curvature relationship using a plastic analysis.

\subsection{Crack propagation}

Figures 11 to 22 depict the tracing of cracks and their order of appearance for various specimens. These figures indicate a variety of cracking occurrences, combining shear, flexural and longitudinal cracks. Longitudinal shear cracks at the top of the slab were created due to the longitudinal shear forces between the shear studs and concrete slab. Also, cracking appears due to the loading points at the top of the slab. Shear cracks had the largest crack widths and significantly contributed to the failure of the composite beam.

\subsection{Crack analysis}

The crack widths were calculated throughout the loading of the beam. Average, maximum, and total values of crack widths were then calculated for each load. Figure 23 shows the trend between number of cracks and applied loads for various specimens. Fiber reinforced concrete had more cracks appear at lower loads and throughout the loading of the composite beam than the control specimens. This effect is also visible when comparing SFRC with and without welded wire mesh. Moreover, the specimens with closer spacing between studs showed smaller number of cracks. 


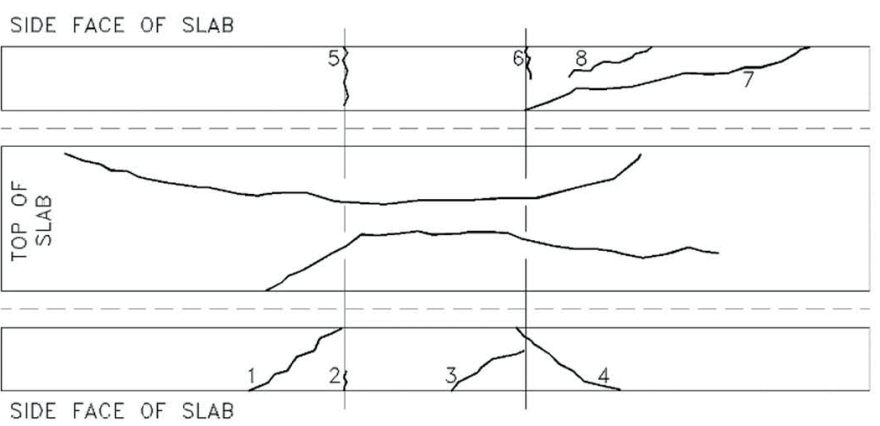

Fig. 11 Cracking for control with $150 \mathrm{~mm}$ (6 in.) stud spacing, specimen 1

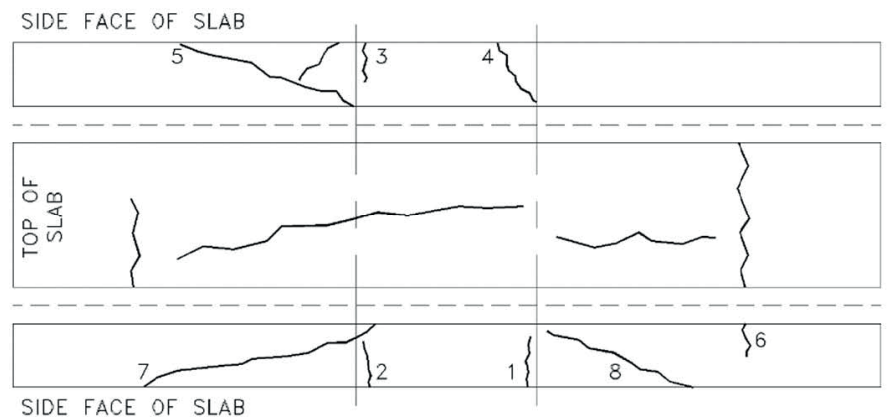

Fig. 12 Cracking for control with $150 \mathrm{~mm}$ (6 in.) stud spacing, specimen 2

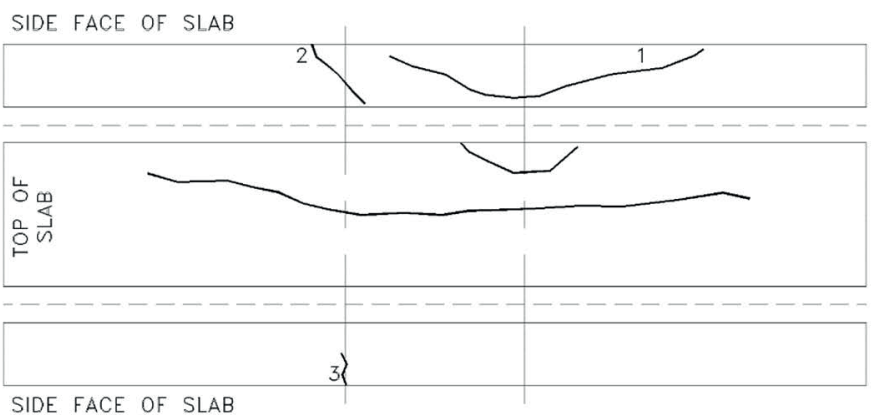

Fig. 13 Cracking for control with $125 \mathrm{~mm}$ (5 in.) stud spacing, specimen 1

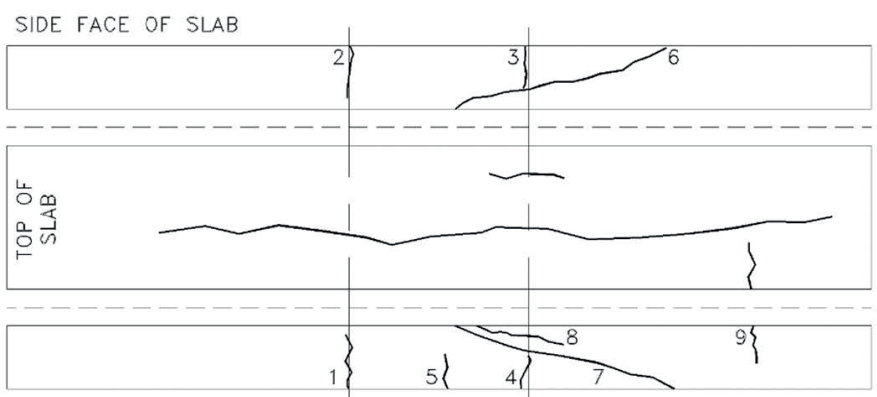

SIDE FACE OF SLAB

Fig. 14 Cracking for control with $125 \mathrm{~mm}$ (5 in.) stud spacing, specimen 2

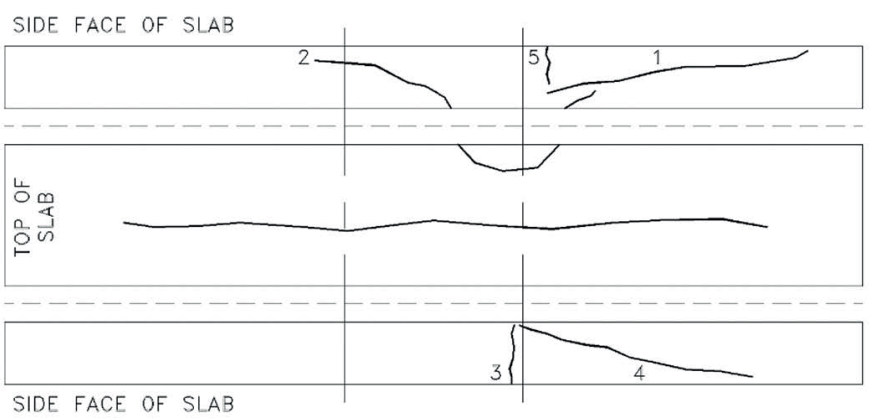

Fig. 15 Cracking for control with $100 \mathrm{~mm}$ (4 in.) stud spacing, specimen 1

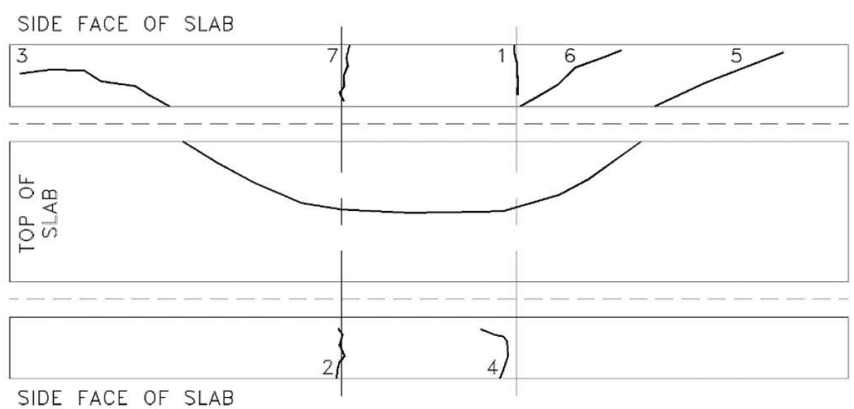

FACE OF SLAB

Fig. 16 Cracking for control with $100 \mathrm{~mm}$ (4 in.) stud spacing, specimen 2

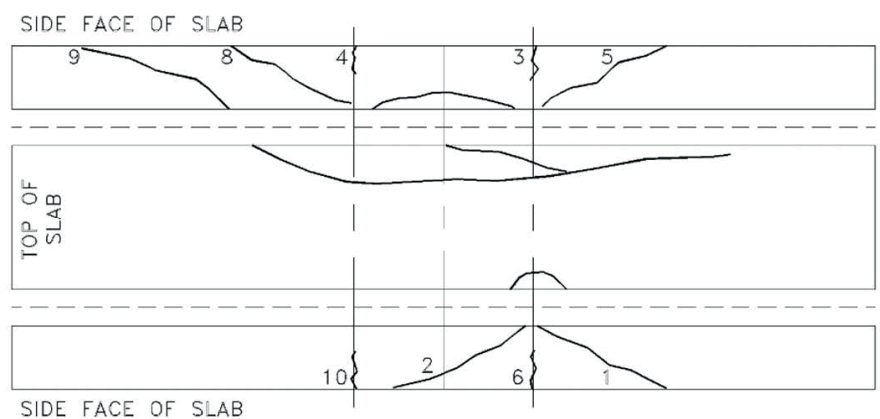

Fig. 17 Cracking for SFRC with $150 \mathrm{~mm}$ (6 in.) stud spacing, specimen 1

SIDE FACE OF SLAB

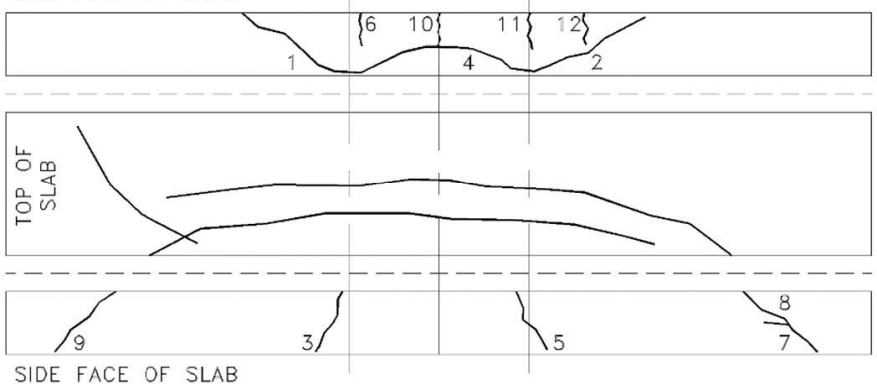

Fig. 18 Cracking for SFRC with $150 \mathrm{~mm}$ (6 in.) stud spacing, specimen 2

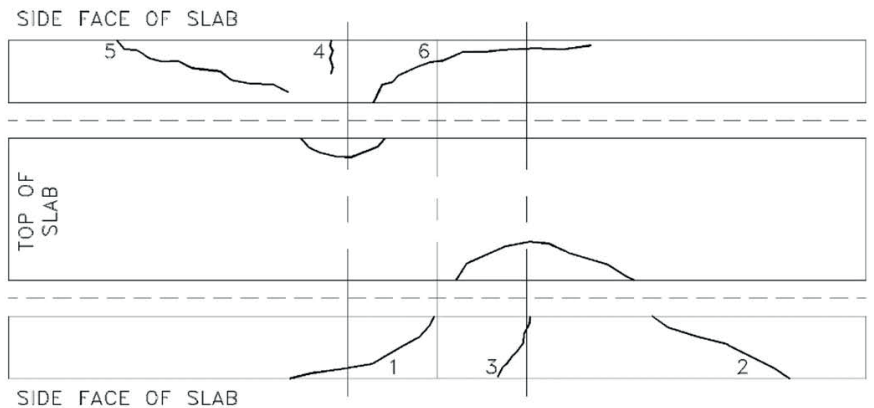

Fig. 19 Cracking for SFRC with $125 \mathrm{~mm}$ (5 in.) stud spacing, specimen 1

SIDE FACE OF SLAB

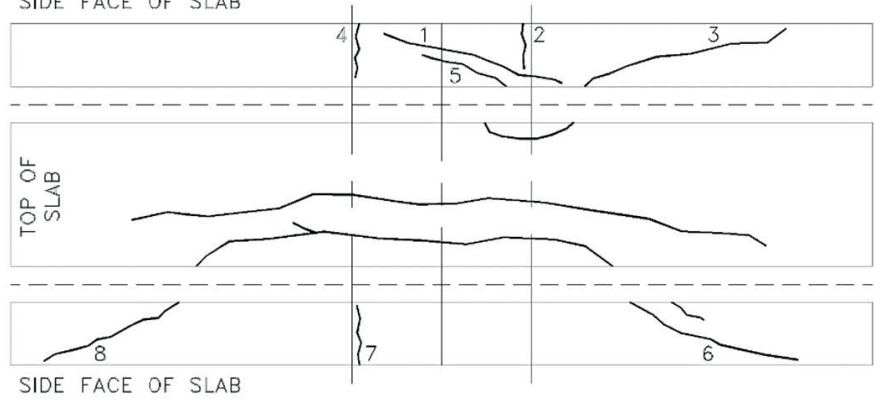

Fig. 20 Cracking for SFRC with $125 \mathrm{~mm}$ (5 in.) stud spacing, specimen 2 


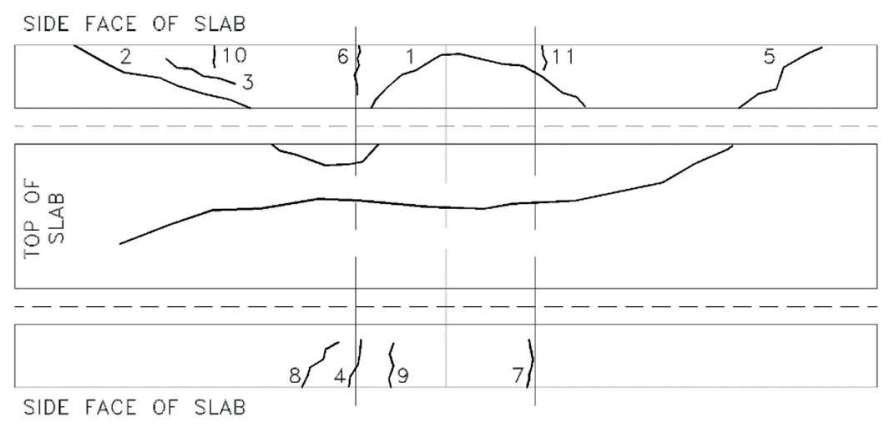

Fig. 21 Cracking for SFRC with $100 \mathrm{~mm}$ (4 in.) stud spacing, specimen 1

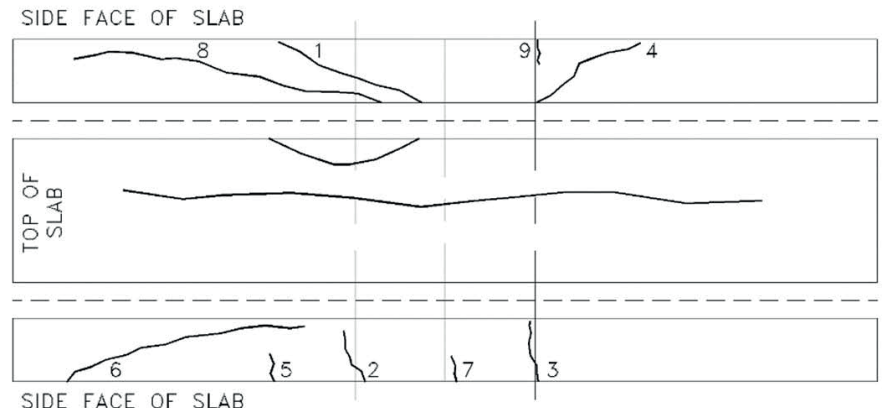

Fig. 22 Cracking for SFRC with $100 \mathrm{~mm}$ (4 in.) stud spacing, specimen 2

Similarly, figure 24 shows the resulted relationships between crack widths and applied loads. These relationships indicate that the SFRC composite beam containing steel mesh had the best performance in respect to controlling crack widths. Further, closer spacing between studs had a substantial impact on cracking as shown in this figure. Furthermore, selected trend lines in this figure indicate the contribution of fiber-reinforcement in limiting crack widths in comparison with plain concrete reinforced with welded-wire mesh only. Such comparison suggests the supplementary nature of steel fibers in arresting cracks.

\subsection{Flexural results and analysis}

Figure 25 contains load-deflection graphs for composite beam subject to flexure. This figure confirms previous results from cracking analysis and indicates better performance of the SFRC specimen with welded wire mesh. In addition, continuously reinforced samples with welded wires were able to withstand larger deflections than samples reinforced with short fibers. The effect of spacing between studs on the peak load is also apparent in this figure. But, the impact of spacing on ultimate deflection is neither clear nor reliable due to limited number of tested samples.

\section{Conclusions}

An experiment was conducted to investigate the cracking behavior of composite beams containing steel fiber-reinforced concrete with $0.75 \%$ by volume hooked-end fibers. Compressive and splitting tensile tests indicated substantial increase in the strength of concrete due to steel fibers by nearly $30 \%$ and $70 \%$, respectively. A total of 12 specimens were prepared for

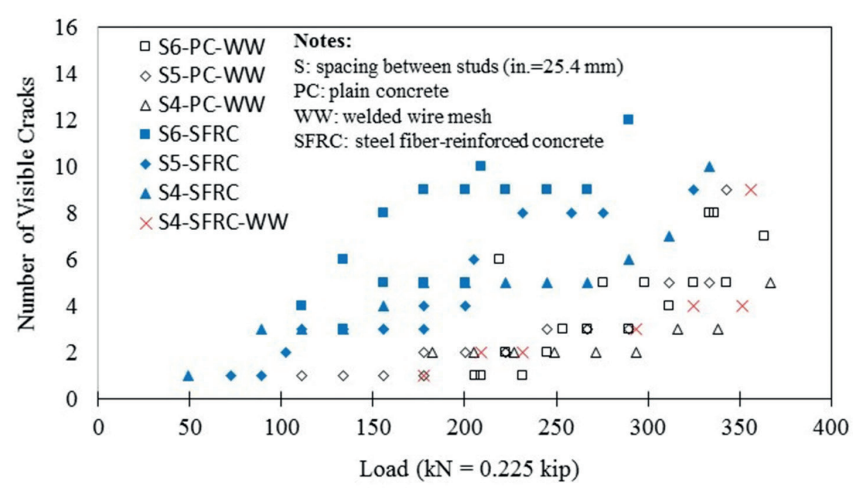

Fig. 23 Number of cracks versus load

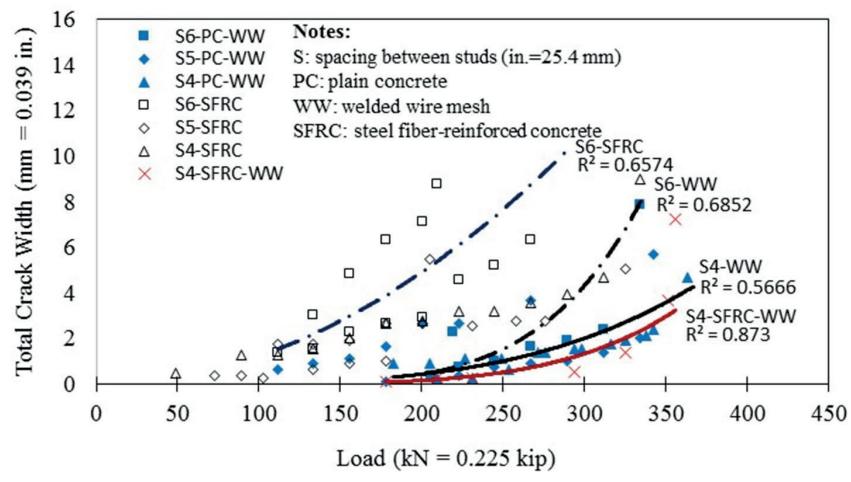

Fig. 24 Crack width versus load

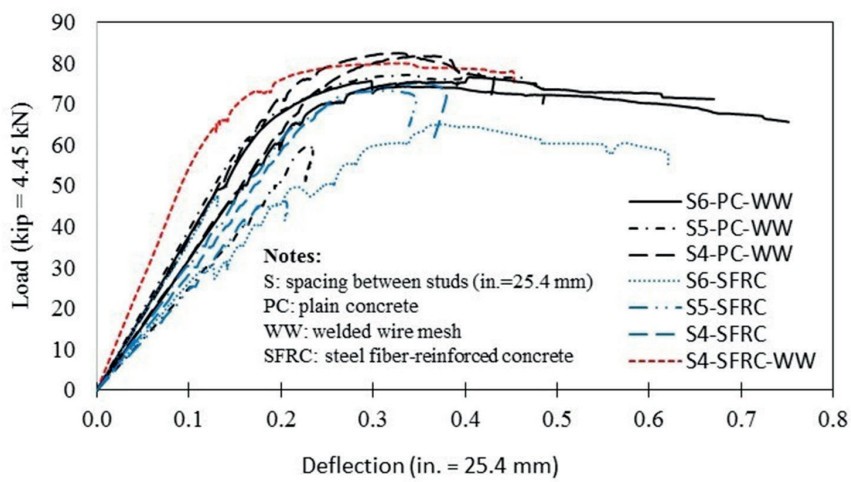

Fig. 25 Load-deflection relationships

four-point flexural tests. Specimens varies in respect to mix design, i.e., plain and fiber-reinforced concrete, and the spacing between studs. Composite beams were designed to achieve cracking in the concrete as the dominant failure mode. Longitudinal and shear cracks were recorded throughout the flexural tests. Observations indicated that longitudinal cracks contributed to the development of shear cracks. The spacing between studs had a major impact on reducing the number and the width of cracks. In addition, the specimen containing both welded wire reinforcement and steel fibers had the best performance in respect to lower number of cracks and smaller crack widths. Comparison of the behavior of this specimen with those containing conventional welded wire mesh only, shows that steel fibers did not have a noticeable impact on number of cracks, but, were effective in reducing the width of cracks. Thus, steel fibers were effective as supplementary reinforcement. 
However, steel fiber-reinforced composite specimens without welded wire mesh did not perform as well as control specimens. Therefore, the effect of application of steel fibers as primary reinforcement remains to be studied further.

\section{Acknowledgement}

The project presented in this article is supported by Fresno State Foundation.

\section{References}

[1] Vayas, I., Iliopoulos, A. "Design of steel-concrete composite bridges to Eurocodes". CRC Press, Taylor \& Francis Group, New York, 2013.

[2] Wang, C-K., Salmon, C. G., Pincheira, J. A., Parra-Montesinos, G. J. "Reinforced Concrete Design". Oxford University Press, New York, 2017.

[3] McComb, C., Tehrani, F. M. "Enhancement of shear transfer in composite deck with mechanical fasteners". Engineering Structures, (88), pp. 251$261,2015$.

https://doi.org/10.1016/j.engstruct.2015.01.046

[4] Ollgaard, J. G., Slutter, R. G., Fisher, J. W. "Shear strength of stud connectors in lightweight and normal-weight concrete". AISC Engineering Journal, 8(2), pp. 55-64, 1971.

[5] Fahmy, E. H., Abu-Amra, T. F. "Longitudinal cracking of concrete slabs in composite beams with ribbed metal deck". Journal of Construction Steel Research, 64(6), pp. 670-679, 2008.

https://doi.org/10.1016/j.jcsr.2007.12.011
[6] Zhao, G., Li, A. "Numerical study of a bonded steel and concrete composite beam". Computers and Structures, 86(19-20), pp. 1830-1838, 2008. https://doi.org/10.1016/j.compstruc.2008.04.002

[7] Jurkiewiez, B., Braymand, S. "Experimental study of a pre-cracked steel-concrete composite beam". Journal of Construction Steel Research, 63(1), pp. 135-144, 2007.

https://doi.org/10.1016/j.jcsr.2006.03.013

[8] Vandewalle, L. "Cracking behaviour of concrete beams reinforced with a combination of ordinary reinforcement and steel fibers". Materials and Structures, 33(3), pp. 164-170, 2000.

https://doi.org/10.1007/BF02479410

[9] AISC. "Specifications for structural steel buildings". ANSI /AISC 36016. American Institute of Steel Construction: Chicago, IL. 2016. https:// www.aisc.org/globalassets/aisc/publications/standards/a360-16-specand-commentary.pdf

[10] Vercodeck. "Steel floor deck catalog VF5". Verco Decking, Inc. 2014. http://www.metaldeck.com/docs/metal-deck/Verco-Interactive-FloorDeck-Catalog-VF5.pdf

[11] Propex. "Novocon 1050 product data sheet". Propex Control Systems Corp. 2007. www.fibermesh.com

[12] AASHTO. "Standard specification for burlap cloth made from jute or kenaf and cotton mats, American Association of State Highway and Transportation Officials". 2009. www.transportation.org

[13] Taucer, F. F., Spacone, E., Filippou, F. C. "A fiber beam-column element for seismic response analysis of reinforced concrete structures". University of California, Berkeley, CA. 1991. https://nisee.berkeley.edu/elibrary/ eerc/1991 